\title{
Immunotherapy for Urothelial Carcinoma: Current Status and Perspectives
}

\author{
Hiroshi Kitamura * and Taiji Tsukamoto \\ Department of Urology, Sapporo Medical University School of Medicine, South 1 West 16, Chuo-ku, \\ Sapporo 060-8543, Japan; E-Mail: taijit@ sapmed.ac.jp \\ * Author to whom correspondence should be addressed; E-Mail: hkitamu @ sapmed.ac.jp; \\ Tel.: +81-11-611-2111 (ext. 3472); Fax: +81-11-612-2709.
}

Received: 7 June 2011; in revised form: 22 July 2011 / Accepted: 26 July 2011 /

Published: 29 July 2011

\begin{abstract}
Intravesical instillation of bacillus Calmette Guérin (BCG) for the treatment of urothelial carcinoma (UC) of the bladder is based on the BCG-induced immune response, which eradicates and prevents bladder cancer. The results of recent studies have suggested that not only major histocompatibility complex (MHC)-nonrestricted immune cells such as natural killer cells, macrophages, neutrophils, etc., but also MHC-restricted CD8 ${ }^{+} \mathrm{T}$ cells play an important role and are one of the main effectors in this therapy. Better understanding of the mechanism of BCG immunotherapy supports the idea that active immunotherapy through its augmented $\mathrm{T}$ cell response can have great potential for the treatment of advanced UC. In this review, progress in immunotherapy for UC is discussed based on data from basic, translational and clinical studies. We also review the escape mechanism of cancer cells from the immune system, and down-regulation of MHC class I molecules.
\end{abstract}

Keywords: immunotherapy; urothelial cancer; cancer vaccine

\section{Introduction}

Since the first report of successful treatment by Morales and associates [1], bacillus Calmette-Guérin (BCG) immunotherapy has been the recommended standard treatment for high grade non-muscle-invasive bladder cancer (NMIBC) [2]. The results of recent studies have suggested that not only innate immunity but also acquired immunity plays an important role in this therapy. In 
contrast, cisplatin-based chemotherapy, e.g., MVAC (methotrexate/vinblastine/doxorubicin/cisplatin), GC (gemcitabine/cisplatin), etc. is a standard systemic therapy for muscle-invasive or metastatic bladder cancer, since urothelial cancer (UC) is chemosensitive. MVAC and GC treatments both result in prolonged survival of up to 14.8 and 13.8 months, respectively, also with long-term followup [3-6]. Several meta-analyses have demonstrated that neoadjuvant cisplatin-containing combination chemotherapy improves overall survival by 5\%-7\% at 5 years, irrespective of the type of definitive treatment used, whereas neither randomized trials nor meta-analyses have provided sufficient data to support the routine use of adjuvant chemotherapy [7-10]. However, up to 50\% of patients are unfit for cisplatin-containing chemotherapy, either due to poor performance status and/or impaired renal function, or to comorbidity that prohibits high-volume hydration [11,12]. Non-platinum combination chemotherapy has produced substantial responses in first- and second-line use, but has not been tested against standard chemotherapy in fit patients or in a purely unfit patient group. There are two main currents for a new paradigm in immunotherapy for UC: (1) enhancement of BCG nonspecific immunotherapy with an adjuvant immunomodulator, e.g., interferon (IFN), granulocyte macrophage colony-stimulating factor (GM-CSF) or specific vaccination for patients with NMIBC, and (2) cancer-specific activation of $\mathrm{T}$ cells for patients with muscle-invasive or metastatic UC, e.g., peptide vaccination and dendritic vaccination. In this review, we focus on the progress in immunotherapy for UC and the escape mechanism of cancer cells from the immune system based on data from basic, translational and clinical studies, as well as the down-regulation of major histocompatibility complex (MHC) class I molecules.

\section{BCG Immunotherapy}

\subsection{Mechanism of BCG Immunotherapy}

After intravesical instillation, BCG infects and is internalized into urothelial and bladder cancer cells via a fibronectin-dependent process mediated by integrins [13-16]. Fibronectin attachment protein (FAP) mediates BCG attachment to bladder cancer cells and the bladder wall following intravesical instillation. Recently Sinn et al. [17] reported that mice pre-immunized with FAP displayed a significant reduction in tumor growth as a result of BCG therapy, suggesting that FAP was also an effective antitumor agent. The interaction of BCG with urothelial cells is thought to result in several immunologically important changes, including induction of chemokines such as interleukin (IL)-1, IL-6, IL-8, IL-17 [18], GM-CSF, tumor necrosis factor (TNF), and the upregulation of intracellular adhesion molecule (ICAM)-1 [19,20]. These cytokines are considered to prepare the ground for cellular assault by causing tumor cells to display molecules that serve as attachment anchors for immune cells, including neutrophils and $\mathrm{T}$ lymphocytes, and activation signals such as ICAM-1, fatty-acid synthetase (FAS), CD40, etc [19,21,22]. A high level of IL-8 production is associated with better clinical responses to BCG [23,24].

After several instillations of BCG, various kinds of immune cells such as neutrophils, macrophages, natural killer (NK) cells, T lymphocytes, and NKT cells are recruited. Seventy-five percent of such immune cells, which are contained in the voided urine of bladder cancer patients after BCG therapy, are composed of neutrophils, followed by $5 \%$ to $10 \%$ macrophages, and $1 \%$ to $3 \%$ NK cells [25]. The 
neutrophils are thought to secrete large amounts of cytokines activating various effector cells. Induction of ICAM-1, MHC class I and II molecules on tumor cells is also important to eliminate these cells in this immunotherapy. It takes five or six BCG instillations to induce these immune reactions and a clinical response [26,27].

Potential effector cells responsible for tumor killing include MHC-nonrestricted cells such as NK cells [28-30], lymphokine-activated killer (LAK) cells [28,31], BCG-activated killer cells [32-34], CD-1-restricted $\mathrm{CD}^{+} \mathrm{T}$ cells,[35] $\gamma \delta \mathrm{T}$ cells [36-38], NKT cells [37-39], neutrophils [40,41], macrophages [42-44], and MHC-restricted $\mathrm{CD}^{+}$and $\mathrm{CD} 4^{+} \mathrm{T}$ cells [45-48]. Of these cells, T lymphocytes are considered to be the most effective effector cells responsible for eliminating cancer cells [49]. Professional antigen-presenting cells such as dendritic cells (DCs) and macrophages can capture, process and present not only mycobacteria but also antigens from apoptotic cancer cells to $\mathrm{T}$ lymphocytes (Figure 1). In a depletion study, both $\mathrm{CD} 8^{+}$and $\mathrm{CD} 4^{+} \mathrm{T}$ cells were found to be essential for the successful antitumor effects of BCG [50]. In our clinical data, the good responders had remarkable infiltration of $\mathrm{CD}^{+}$cells after BCG therapy [47].

Figure 1. Suggested cascade of immune response induced by intravesical BCG instillation.

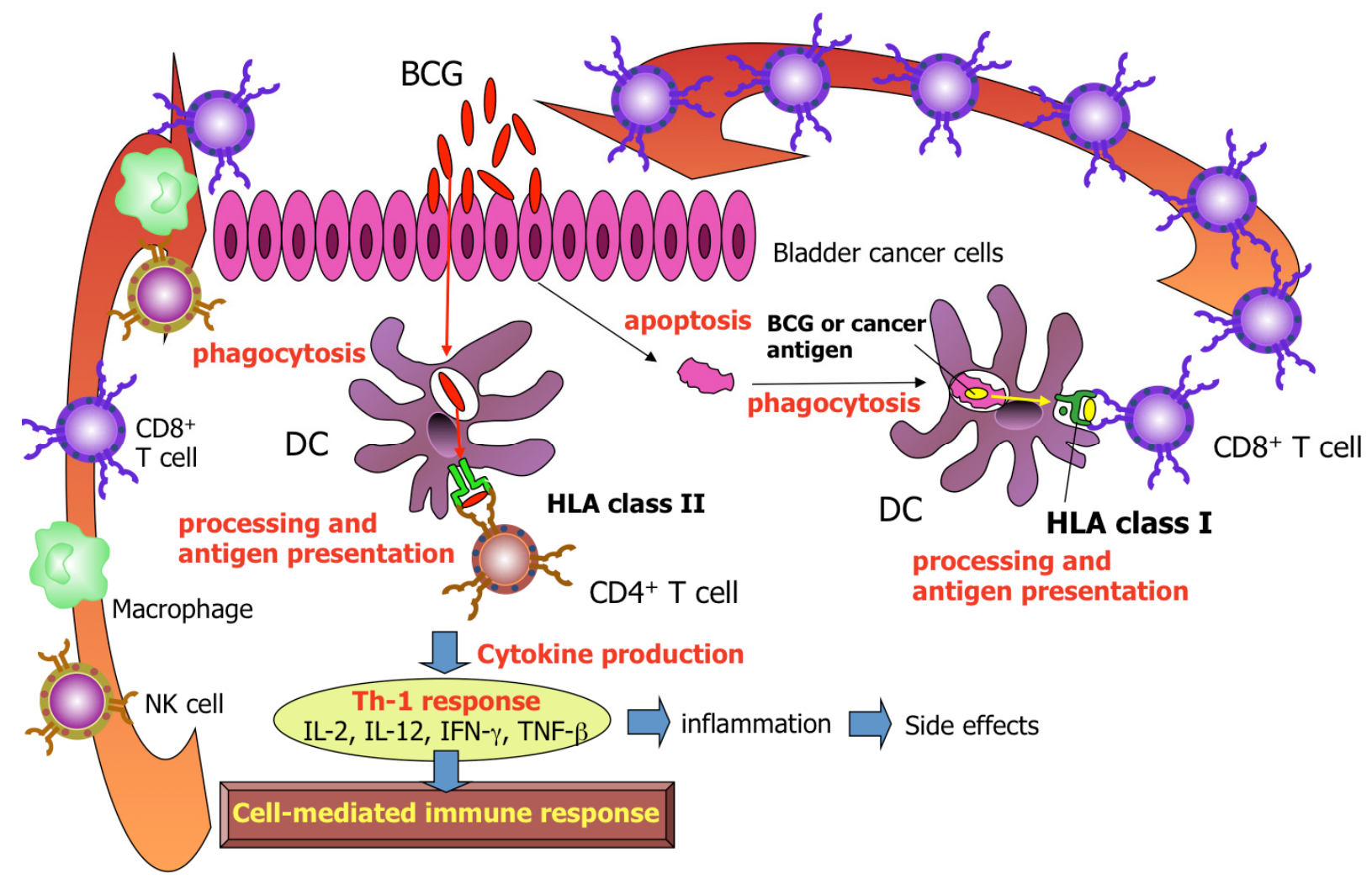

Macrophages play important roles not only in antigen presentation but also cytotoxicity. BCG infection may result in up-regulated expression of adhesion molecules such as lymphocyte function-associated antigen-1 (LFA-1) or apoptosis-inducing molecules such as Fas ligand and tumor necrosis factor-related apoptosis-inducing ligand (TRAIL) on macrophages [51-53]. Macrophages can bind to bladder cancer cells via these surface proteins and kill them [48]. Th1 cytokines such as IFN- $\gamma$, IL-12, and IL-18 play positive roles in BCG-induced macrophage cytotoxicity toward bladder cancer cells [54,55]. In contrast, Ayari et al. [56] reported that high levels of tumor infiltration by CD83 ${ }^{+}$ 
tumor-infiltrating $\mathrm{DCs}$ and $\mathrm{CD}^{+} 8^{+}$tumor-associated macrophages prior to $\mathrm{BCG}$ therapy were associated with an increased risk of recurrence. These results may be explained by a switch from a favorable Th1 response of DCs in patients exposed to few BCG instillations to a less favorable Th2 response on repeated BCG instillation [56]. Furthermore, results from some experimental models indicate that BCG therapy induces upregulation of IL-17 and its receptors, and that IL-17 promotes the growth of bladder cancer cells [57,58]. Thus it is suggested that there is a relative predominance of Th1 and Th17 responses and a relative suppression of Th2 and regulatory T cells [49]. However, a recent randomized study showed that autologous intravesical macrophage cell therapy (BEXIDEM®) failed to demonstrate non-inferiority in recurrence rates to intravesical BCG therapy [59]. This result suggests that macrophages from peripheral blood may not elicit antitumor effects as powerful as the immunity induced by BCG instillation.

Chemokines induced by BCG, including IL-8, IL-18, interferon-inducible protein (IP)-10, monocyte chemotactic protein (MCP)-1, MCP-3, macrophage inflammatory protein (MIP)-1 $\alpha$, and MIP-1 $\beta$, can recruit various immune cells [24,60-63]. There are several reports in which urinary chemokine secretion after intravesical BCG instillation correlated with the clinical response [23,24,62,64,65]. BCG activates innate components of the immune system through toll-like receptor (TLR) 2, TLR4 [66], and TLR9 [67] and induces IFN- $\gamma$ production in human DCs via TLR2 [68]. BCG can also induce TRAIL expression on polymorphonuclear neutrophils [69]. High TRAIL protein levels in the urine of bladder cancer patients treated with BCG are associated with a favorable response to treatment [70].

\subsection{Clinical Evidence of Intravesical BCG Therapy}

There is no doubt that BCG immunotherapy is an effective therapeutic option for patients with NMIBC. Many prospective randomized studies and meta-analyses have demonstrated that adjuvant BCG therapy after transurethral resection (TUR) for TaT1 disease reduces the risk of recurrence and/or increases the disease-free interval compared with TUR alone or TUR with intravesical chemotherapy [71-78]. Intravesical BCG also reduces the risk of short and long-term treatment failure in patients with carcinoma in situ (CIS), as determined by meta-analysis [79].

Based on the results of meta-analyses [72,75,80,81], BCG therapy given on a maintenance schedule is recommended for patients with intermediate and high risks of progression [82]. Of the randomized trials [83-87] for maintenance BCG therapy, however, only one study [86] demonstrated a benefit for recurrence-free survival of maintenance therapy. It is possible that more patients included in the positive study contributed to the positive results in those meta-analyses. Furthermore, there is no consensus on the protocol for the maintenance schedule, e.g., every 1, 3 or 6 months, or for 1, 2 or 3 years.

The latest European Association of Urology (EAU) guidelines on NMIBC propose the following recommendations: (1) in patients with TaT1 tumors at intermediate or high risk of recurrence and intermediate risk of progression, one intermediate instillation of chemotherapy should be followed by a minimum 1 year BCG treatment or by further instillations of chemotherapy (grade A); (2) in patients at high risk for tumor progression, intravesical BCG for at least 1 year is recommended (grade A), and (3) in patients with bladder CIS, intravesical BCG is recommended for at least 1 year (grade A) [82]. Thus BCG immunotherapy is the mainstay for adjuvant therapy for patients with NMIBC. However, there is a limitation in the efficacy and tolerance of BCG therapy. Although intravesical BCG provides 
a complete response in $55 \%$ to $65 \%$ of TaT1 and $70 \%$ to $75 \%$ of CIS [88,89], 30\% fail to respond to BCG or relapse within the first 5 years after treatment and nearly $90 \%$ recur by 15 years [88-90]. Furthermore, approximately $20 \%$ of patients are BCG intolerant and unable to complete treatment due to side effects [91]. BCG toxicity is not responsible for an improved outcome [92]. Thus there is a need for new immunotherapies providing better outcomes with less toxicity than conventional intravesical BCG therapy.

\subsection{Immunomodulator of $B C G$}

As mentioned above, intravesical BCG instillation can elicit cytotoxic immune reactions against bladder cancer cells through both innate and adoptive immunity. To augment antitumor responses and limit side effects, combination of BCG and immunomodulating agents such as IFN- $\alpha$ has been evaluated. In a multicenter phase II trial of combination BCG plus IFN- $\alpha 2 b$, the 2 -year recurrence-free survival rates were $59 \%$ and $45 \%$ in patients naïve to BCG and those having BCG failure, respectively [93]. A large randomized study of BCG vs. BCG plus IFN- $\alpha 2 b$ in BCG-naïve patients with NMIBC revealed that $\mathrm{BCG}$ plus IFN- $\alpha 2 \mathrm{~b}$ did not decrease tumor recurrence and increased the prevalence of side effects compared to BCG alone [94]. To date, there have been no randomized prospective studies that have evaluated IFN- $\alpha 2 b$ in cases of BCG failure [94]. Another randomized study of mitomycin C followed by BCG vs. BCG plus IFN- $\alpha 2 b$ showed that no benefit was obtained by alternating IFN- $\alpha 2 b$ with BCG [95]. Thus addition of IFN- $\alpha$ to BCG does not seem to enhance the antitumor effects of BCG immunotherapy.

\section{Active Immunotherapy for Advanced UC}

Active immunotherapy has the potential to stimulate the immune system, particularly cellular adaptive immunity of the patient to attack the tumor cells. To successfully become recognized as malignant, the response has to be strengthened by vaccination strategies so that target cells can be recognized and eliminated effectively by effector cells such as cytotoxic T lymphocytes (CTLs) [96]. Tumor-infiltrating lymphocytes (TILs) in patients with melanoma, colon cancer and ovarian cancer are associated with favorable clinical outcomes [97]. Several studies of breast cancer indicated that immunological processes, including the development of TILs and disappearance of regulatory T cells, may influence the clinical response to neoadjuvant chemotherapy [98,99]. Lipponen et al. [100] investigated the prognostic value of TILs in a cohort of 514 patients with bladder cancer, and reported that a large density of TILs predicted an unfavorable prognosis in papillary tumors, whereas it was a sign of good prognosis in nodular and T3-T4 tumors. Sharma et al. [101] showed that patients with T2-T4 disease and higher numbers of $\mathrm{CD}^{+}$TILs had better disease-free survival and overall survival than those with similar-stage bladder cancer and fewer intratumoral CD8 ${ }^{+}$TILs. Furthermore, Marits et al. [102] demonstrated that the sentinel node lymphocytes from patients who underwent radical cystectomy for bladder cancer displayed a retained immunological function upon in vitro restimulation with the tumor antigen, and proposed the use of those lymphocytes as the primary source of immune effector cells for immunotherapy. These data support the idea that active immunotherapy through the augmented T-cell response can have great potential for the treatment of advanced bladder cancer. 
Active immunotherapeutic strategies include cancer vaccinations using autologous or allogeneic whole tumor cells or tumor lysates, tumor-derived peptides, gene-modified autologous or allogeneic tumor cells, viral vectors carrying genes encoding for tumor antigens, naked DNA plasmids encoding for tumor antigens, autologous APCs presenting tumor antigens, etc [103]. To date, however, there have been few phase I or II clinical trials of active immunotherapy for bladder cancer published (Table 1).

Table 1. Overview of phase I and II clinical trials of active immunotherapy in bladder cancer.

\begin{tabular}{|c|c|c|c|c|c|}
\hline Author & Approach & Disease stage & No. $\mathbf{P t}$ & Phase & Results \\
\hline $\begin{array}{l}\text { Sharma et al. } \\
\text { (2008) [104] }\end{array}$ & $\begin{array}{l}\text { NY-ESO-1 protein } \\
\text { vaccine + BCG i.d. + } \\
\text { GM-CSF }\end{array}$ & $\begin{array}{l}\text { Radically operated } \\
\text { UC without } \\
\text { metastasis (adjuvant } \\
\text { setting) }\end{array}$ & 6 & I & $\begin{array}{l}\mathrm{Ag} \text {-specific } \mathrm{Ab} \text { in } 5 / 6 \\
\text { Pts, CD8 T cell response } \\
\text { in } 1 / 6 \mathrm{Pts}, \mathrm{CD} 4 \mathrm{~T} \text { cell } \\
\text { response in } 6 / 6 \mathrm{Pts} \text {, no } \\
\text { severe AE }\end{array}$ \\
\hline $\begin{array}{l}\text { Honma et al. } \\
\text { (2009) [105] }\end{array}$ & $\begin{array}{l}\text { Survivin peptide } \\
\text { vaccine }\end{array}$ & $\begin{array}{l}\text { Refractory recurrent } \\
\text { UC }\end{array}$ & 9 & I & $\begin{array}{l}\text { CD8 T cell response in } \\
5 / 9 \mathrm{Pts} \text {, tumor reduction } \\
\text { in } 2 / 9 \mathrm{Pts}, \text { no severe } \mathrm{AE}\end{array}$ \\
\hline $\begin{array}{l}\text { Sherif et al. } \\
\text { (2010) [107] }\end{array}$ & $\begin{array}{l}\text { Reinfusion of } \\
\text { autologous T-helper } \\
\text { cells }\end{array}$ & $\begin{array}{l}\text { T2-T4 N1-2 M0-1 } \\
\text { bladder cancer }\end{array}$ & 12 & I & $\begin{array}{l}\text { Feasible in } 6 / 12 \text { Pts, } \\
\text { technical failure in } 6 / 12 \\
\text { Pts, no severe AE }\end{array}$ \\
\hline $\begin{array}{l}\text { Malmström } \\
\text { et al. }(2010) \\
{[108]}\end{array}$ & $\begin{array}{l}\text { Adenoviral vector } \\
\text { expressing CD40 } \\
\text { ligand (intravesical) }\end{array}$ & $\begin{array}{l}\text { MIBC scheduled } \\
\text { cystectomy (phase I), } \\
\text { Ta disease (phase II) }\end{array}$ & 8 & $\mathrm{I} / \mathrm{II}$ & $\begin{array}{l}\text { Enhancement of } \mathrm{T} \text { cell } \\
\text { infiltration and IFN- } \gamma \\
\text { production, reduction of } \\
\text { circulating Treg, AE of } \\
\text { minor local pain }\end{array}$ \\
\hline $\begin{array}{l}\text { Matsumoto } \\
\text { et al. }(2010) \\
{[109]}\end{array}$ & $\begin{array}{l}\text { Personalized peptide } \\
\text { vaccine }\end{array}$ & $\begin{array}{l}\text { Advanced UC } \\
\text { (MVAC failure) }\end{array}$ & 10 & I & $\begin{array}{l}1 \mathrm{CR}, 1 \mathrm{PR}, 2 \mathrm{SD}, \mathrm{PFS} \\
3.0 \text { months, OS } 8.9 \\
\text { months, no severe AE }\end{array}$ \\
\hline
\end{tabular}

i.d.: intradermal; Ag: antigen; Ab antibody; AE: adverse event; Treg: regulatory T cell; MVAC: methotrexate, vinblastine, adriamycin and cisplatin; CR: complete response; PR: partial response; SD: stable disease; PFS: progression-free survival; OS: overall survival

Sharma et al. evaluated the safety and immunogenicity of a recombinant NY-ESO-1 protein vaccine, which was administered with GM-CSF and BCG as immunologic adjuvants, in a cohort of UC patients whose cancer cells expressed NY-ESO-1, a cancer/testis antigen [104]. Most of the patients exhibited NY-ESO-1-specific antibody and $\mathrm{CD}^{+} \mathrm{T}$ cell responses, but $\mathrm{CD}^{+} \mathrm{T}$ cell responses were observed in one patient. All patients tolerated the vaccine therapy well and completed all scheduled administrations without any difficulties, although one patient had a grade 2 injection-site reaction consisting of induration and erythema. Honma et al. [105] reported the results of a phase I study of survivin peptide vaccination for advanced UC. HLA-A24-restricted survivin-2B peptide was subcutaneously administered with incomplete Freund's adjuvant. Survivin, a member of the inhibitor of apoptosis protein family, is overexpressed in $88 \%$ of bladder cancers, but not in normal adult tissues [106]. This vaccination targeting survivin-expressing cells induced epitope-specific CTLs in five of nine patients, and provided tumor reduction and long-term stable disease in two patients. The vaccination was well 
tolerated in all patients without severe adverse events (AEs). Sherif et al. [107] harvested T cells from the nearest draining nodes at cystectomy, and reinfused the autologous T-helper cells after in vitro culture and expansion. Tumor-specific-T-helper cells were obtained and reinfused in six of 12 patients without major AEs, but the clinical benefit has not yet been evaluated. Malmström et al. [108] carried out a phase I/II study of intravesical administration of adenoviral vectors expressing a CD40 ligand (AdCD40L). CD40L is a potent Th1 immune stimulator that elicits a robust antitumor response. They reported that gene transfer was detected in biopsies, bladders were heavily infiltrated with $\mathrm{T}$ cells, and that therapy was well tolerated with low-grade local pain alone. This study suggests that local AdCD40L therapy is potentially effective for bladder cancer, but there are no data on clinical outcomes. Matsumoto et al. [109] performed a phase I study of personalized peptide vaccination. Cocktail peptides that might induce HLA-A24-restricted or HLA-A2-restricted and tumor-specific CTL activity were administered subcutaneously. Epitope-specific $\mathrm{T}$ cell and antibody responses were observed in eight of 10 patients with one complete response, one partial response and two cases of stable disease. The vaccination was well tolerated with no severe AEs.

The results of the phase I and I/II clinical trials suggest that active immunotherapy for UC induces immune and antitumor responses without severe AEs. However, further clinical studies including phases II and III are needed to determine whether such therapies really provide clinical benefits for patients with UC.

\section{Escape Mechanism of Cancer Cells from the Immune System in UC}

The rationale for studies of active immunotherapy is supported by strong cellular immune responses when introducing cancer-specific CTLs from patients. Immune cells must be activated at the tumor site to manifest appropriate effector mechanisms such as direct lysis or cytokine secretion capable of causing tumor destruction, in addition to the need for a sufficient number of the cells. However, there have been many cases in which no clinical response was achieved regardless of good immune responses in immunomonitoring assays. Therefore, tumor cell factors should be evaluated for development of the clinical responses in cancer immunotherapy.

Human leukocyte antigen (HLA), MHC in humans, class I has a critical role in the recognition and lysis of tumor cells by CTLs, and defects in antigen presentation could allow tumors to escape killing by CTLs [110]. Down-regulation of HLA class I in cancer cells is disadvantageous for presentation of a cancer antigen and its peptide to the patient's immune system [111]. HLA class I is down-regulated in approximately $30 \%$ of bladder cancers $[106,112]$. This is a significant prognostic factor in patients undergoing BCG immunotherapy [47] and radical cystectomy for treatment of muscle-invasive disease [112]. It is suggested that tumor cells with down-regulated HLA class I escape from T cell recognition and that, in such cases, BCG immunotherapy is not effective for patients with bladder cancer. In an animal model using chemically induced bladder cancer, the cytotoxic activity of $\mathrm{T}$ cells from rats on tumor cells with low MHC class I expression was decreased as compared with tumor cells with high MHC-I expression [113]. Another recent study using surgical specimens of human bladder cancer demonstrated the changes in HLA class I expression during tumor development [114]. This suggests that immunotherapy stimulates an additional strong cycle of immunoselection, eliminating cells with low HLA and/or changes in it, but cancer cells with more profound HLA class I alterations 
can escape the immune system and develop recurrent tumors. Thus, it is essential not only to analyze the mechanisms of escape from the immune system but also to develop an immunotherapeutic approach targeting the inhibition of the escape, e.g., upregulation of HLA class I on cancer cells [115].

Regulatory $\mathrm{T}$ cells (Tregs) are a population of $\mathrm{T}$ cells that regulate the activation of both effector/helper $\mathrm{T}$ and $\mathrm{B}$ cells. Many studies with cancer patients have demonstrated that the prevalence of Tregs is significantly high in cancerous lesions as compared to healthy controls, and the percentage of Tregs among TILs positively correlates with a significantly lower survival rate [116]. In contrast, Winerdal et al. [117] reported that the infiltration of Tregs in bladder cancer was also associated with improved prognosis. Thus the immune escape mechanism through Treg is still controversial in bladder cancer.

Myeloid-derived suppressor cells (MDSCs) represent a heterogeneous population of

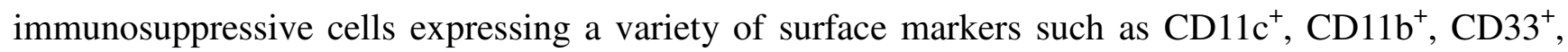
$\mathrm{CD} 4^{+}$and $\mathrm{CD} 15^{+}$. The frequency of these cells also positively correlates with the incidence of recurrence or metastatic disease in patients [116]. Eruslanov et al. [118] have demonstrated that highly activated inflammatory myeloid cells inhibiting in vitro $\mathrm{T}$ cell proliferation through induction of Tregs in peripheral blood and tumor tissues from patients with bladder cancer represent a source of multiple chemokines/cytokines and may contribute to inflammation and immune dysfunction in bladder cancer. Further studies are needed to confirm these results, examine the underlying mechanisms in detail, and investigate the prognostic impact on survival.

\section{Conclusions and Perspectives}

Various studies have indicated that immunotherapy can eliminate bladder cancer cells, but it is not yet capable of curing bladder cancer, and other therapeutic modalities such as surgery and chemotherapy are still required for this purpose. BCG immunotherapy is effective for NMIBC but does not always control its recurrence and is ineffective for MIBC, indicating that BCG therapy may not induce powerful specific antitumor immunity or immunological memory. However, based on the efficacy and recent advances in understanding of the mechanism of BCG immunotherapy, active immunotherapy has great potential as a weapon against even advanced urothelial carcinoma. Although an HLA class I-restricted peptide vaccine eliciting epitope-specific CTLs seems to be one of the most promising approaches at present, this can also induce $\mathrm{CD}^{+} \mathrm{T}$ cell tolerance $[119,120]$, with low response rates in clinical trials. Better understanding of the innate and adaptive immune responses, and of the immune escape mechanisms underlying immunological tolerance, and acknowledgment of the importance of adaptive immunity for control of tumor growth are necessary to develop a more comprehensive immunotherapeutic approach [121]. Alternatively, combination with chemotherapy, molecular-targeting therapy or surgery can be effective ways to apply active immunotherapy to clinical use. 


\section{References}

1. Morales, A.; Eidinger, D.; Bruce, A.W. Intracavitary Bacillus Calmette-Guerin in the treatment of superficial bladder tumors. J. Urol. 1976, 116, 180-183.

2. Herr, H.W.; Morales, A. History of bacillus Calmette-Guerin and bladder cancer: An immunotherapy success story. J. Urol. 2008, 179, 53-56.

3. Sternberg, C.N.; Yagoda, A.; Scher, H.I.; Watson, R.C.; Herr, H.W.; Morse, M.J.; Sogani, P.C.; Vaughan, E.D., Jr.; Bander, N.; Weiselberg, L.R.; et al. M-VAC (methotrexate, vinblastine, doxorubicin and cisplatin) for advanced transitional cell carcinoma of the urothelium. J. Urol. 1988, 139, 461-469.

4. Sternberg, C.N.; Yagoda, A.; Scher, H.I.; Watson, R.C.; Geller, N.; Herr, H.W.; Morse, M.J.; Sogani, P.C.; Vaughan, E.D.; Bander, N.; et al. Methotrexate, vinblastine, doxorubicin, and cisplatin for advanced transitional cell carcinoma of the urothelium. Efficacy and patterns of response and relapse. Cancer 1989, 64, 2448-2458.

5. von der Maase, H.; Hansen, S.W.; Roberts, J.T.; Dogliotti, L.; Oliver, T.; Moore, M.J.; Bodrogi, I.; Albers, P.; Knuth, A.; Lippert, C.M.; et al. Visseren-Grul, C.M.; Conte, P.F. Gemcitabine and cisplatin versus methotrexate, vinblastine, doxorubicin, and cisplatin in advanced or metastatic bladder cancer: results of a large, randomized, multinational, multicenter, phase III study. Amer. J. Clin. Oncol. 2000, 18, 3068-3077.

6. $\quad$ von der Maase, H.; Sengelov, L.; Roberts, J.T.; Ricci, S.; Dogliotti, L.; Oliver, T.; Moore, M.J.; Zimmermann, A.; Arning, M. Long-term survival results of a randomized trial comparing gemcitabine plus cisplatin, with methotrexate, vinblastine, doxorubicin, plus cisplatin in patients with bladder cancer. Amer. Soc. Clin. 2005, 23, 4602-4608.

7. Sherif, A.; Holmberg, L.; Rintala, E.; Mestad, O.; Nilsson, J.; Nilsson, S.; Malmstrom, P.U. Neoadjuvant cisplatinum based combination chemotherapy in patients with invasive bladder cancer: a combined analysis of two Nordic studies. Eur. Urol. 2004, 45, 297-303.

8. Neoadjuvant chemotherapy in invasive bladder cancer: Update of a systematic review and meta-analysis of individual patient data advanced bladder cancer (ABC) meta-analysis collaboration. Eur. Urol. 2005, 48, 202-206.

9. Adjuvant chemotherapy in invasive bladder cancer: a systematic review and meta-analysis of individual patient data Advanced Bladder Cancer (ABC) Meta-analysis Collaboration. Eur. Urol. 2005, 48, 189-201.

10. Stenzl, A.; Cowan, N.C.; De Santis, M.; Kuczyk, M.A.; Merseburger, A.S.; Ribal, M.J.; Sherif, A.; Witjes, J.A. Treatment of muscle-invasive and metastatic bladder cancer: Update of the EAU guidelines. Eur. Urol. 2011, 59, 1009-1018.

11. Balducci, L. Evidence-based management of cancer in the elderly. Cancer Contr. 2000, 7 , 368-376.

12. Nogue-Aliguer, M.; Carles, J.; Arrivi, A.; Juan, O.; Alonso, L.; Font, A.; Mellado, B.; Garrido, P.; Saenz, A. Gemcitabine and carboplatin in advanced transitional cell carcinoma of the urinary tract: an alternative therapy. Cancer 2003, 97, 2180-2186. 
13. Kavoussi, L.R.; Brown, E.J.; Ritchey, J.K.; Ratliff, T.L. Fibronectin-mediated Calmette-Guerin bacillus attachment to murine bladder mucosa. Requirement for the expression of an antitumor response. J. Clin. Invest. 1990, 85, 62-67.

14. Becich, M.J.; Carroll, S.; Ratliff, T.L. Internalization of bacille Calmette-Guerin by bladder tumor cells. J. Urol. 1991, 145, 1316-1324.

15. Kuroda, K.; Brown, E.J.; Telle, W.B.; Russell, D.G.; Ratliff, T.L. Characterization of the internalization of bacillus Calmette-Guerin by human bladder tumor cells. J. Clin. Invest. 1993, 91, 69-76.

16. Luo, Y.; Szilvasi, A.; Chen, X.; DeWolf, W.C.; O'Donnell, M.A. A novel method for monitoring Mycobacterium bovis BCG trafficking with recombinant BCG expressing green fluorescent protein. Clin. Diagn. Lab. Immunol. 1996, 3, 761-768.

17. Sinn, H.W.; Elzey, B.D.; Jensen, R.J.; Zhao, X.; Zhao, W.; Ratliff, T.L. The fibronectin attachment protein of bacillus Calmette-Guerin (BCG) mediates antitumor activity. Cancer Immunol. Immunother. 2008, 57, 573-579.

18. Takeuchi, A.; Dejima, T.; Yamada, H.; Shibata, K.; Nakamura, R.; Eto, M.; Nakatani, T.; Naito, S.; Yoshikai, Y. IL-17 production by gammadelta T cells is important for the antitumor effect of Mycobacterium bovis bacillus Calmette-Guerin treatment against bladder cancer. Eur. J. Immunol. 2011, 41, 246-251.

19. Alexandroff, A.B.; Jackson, A.M.; O'Donnell, M.A.; James, K. BCG immunotherapy of bladder cancer: 20 years on. Lancet 1999, 353, 1689-1694.

20. Simons, M.P.; O'Donnell, M.A.; Griffith, T.S. Role of neutrophils in BCG immunotherapy for bladder cancer. Urol. Oncol. 2008, 26, 341-345.

21. Jackson, A.M.; Alexandroff, A.B.; McIntyre, M.; Esuvaranathan, K.; James, K.; Chisholm, G.D. Induction of ICAM 1 expression on bladder tumours by BCG immunotherapy. J. Clin. Pathol. 1994, 47, 309-312.

22. Alexandroff, A.B.; Robins, R.A.; Murray, A.; James, K. Tumour immunology: false hopes-New horizons? Immunol. Today 1998, 19, 247-250.

23. Thalmann, G.N.; Dewald, B.; Baggiolini, M.; Studer, U.E. Interleukin-8 expression in the urine after bacillus Calmette-Guerin therapy: A potential prognostic factor of tumor recurrence and progression. J. Urol. 1997, 158, 1340-1344.

24. Thalmann, G.N.; Sermier, A.; Rentsch, C.; Mohrle, K.; Cecchini, M.G.; Studer, U.E. Urinary Interleukin- 8 and 18 predict the response of superficial bladder cancer to intravesical therapy with bacillus Calmette-Guerin. J. Urol. 2000, 164, 2129-2133.

25. De Boer, E.C.; De Jong, W.H.; van der Meijden, A.P.; Steerenberg, P.A.; Witjes, J.A.; Vegt, P.D.; Debruyne, F.M.; Ruitenberg, E.J. Presence of activated lymphocytes in the urine of patients with superficial bladder cancer after intravesical immunotherapy with bacillus Calmette-Guerin. Cancer Immunol. Immunother. 1991, 33, 411-416.

26. Prescott, S.; James, K.; Hargreave, T.B.; Chisholm, G.D.; Smyth, J.F. Intravesical Evans strain BCG therapy: Quantitative immunohistochemical analysis of the immune response within the bladder wall. J. Urol. 1992, 147, 1636-1642. 
27. Jackson, A.M.; Alexandroff, A.B.; Kelly, R.W.; Skibinska, A.; Esuvaranathan, K.; Prescott, S.; Chisholm, G.D.; James, K. Changes in urinary cytokines and soluble intercellular adhesion molecule-1 (ICAM-1) in bladder cancer patients after bacillus Calmette-Guerin (BCG) immunotherapy. Clin. Exp. Immunol. 1995, 99, 369-375.

28. Wang, M.H.; Flad, H.D.; Bohle, A.; Chen, Y.Q.; Ulmer, A.J. Cellular cytotoxicity of human natural killer cells and lymphokine-activated killer cells against bladder carcinoma cell lines. Immunol. Lett. 1991, 27, 191-197.

29. Brandau, S.; Riemensberger, J.; Jacobsen, M.; Kemp, D.; Zhao, W.; Zhao, X.; Jocham, D.; Ratliff, T.L.; Bohle, A. NK cells are essential for effective BCG immunotherapy. Int. J. Cancer 2001, 92, 697-702.

30. Liu, W.; O'Donnell, M.A.; Chen, X.; Han, R.; Luo, Y. Recombinant bacillus Calmette-Guerin (BCG) expressing interferon-alpha 2B enhances human mononuclear cell cytotoxicity against bladder cancer cell lines in vitro. Cancer Immunol. Immunother. 2009, 58, 1647-1655.

31. Shemtov, M.M.; Cheng, D.L.; Kong, L.; Shu, W.P.; Sassaroli, M.; Droller, M.J.; Liu, B.C. LAK cell mediated apoptosis of human bladder cancer cells involves a $\mathrm{pH}$-dependent endonuclease system in the cancer cell: possible mechanism of BCG therapy. J. Urol. 1995, 154, 269-274.

32. Bohle, A.; Thanhauser, A.; Ulmer, A.J.; Ernst, M.; Flad, H.D.; Jocham, D. Dissecting the immunobiological effects of Bacillus Calmette-Guerin (BCG) in vitro: Evidence of a distinct BCG-activated killer (BAK) cell phenomenon. J. Urol. 1993, 150, 1932-1937.

33. Thanhauser, A.; Bohle, A.; Flad, H.D.; Ernst, M.; Mattern, T.; Ulmer, A.J. Induction of bacillus-Calmette-Guerin-activated killer cells from human peripheral blood mononuclear cells against human bladder carcinoma cell lines in vitro. Cancer Immunol. Immunother. 1993, 37, 105-111.

34. Brandau, S.; Suttmann, H.; Riemensberger, J.; Seitzer, U.; Arnold, J.; Durek, C.; Jocham, D.; Flad, H.D.; Bohle, A. Perforin-mediated lysis of tumor cells by Mycobacterium bovis Bacillus Calmette-Guerin-activated killer cells. Clin. Cancer Res. 2000, 6, 3729-3738.

35. Kawashima, T.; Norose, Y.; Watanabe, Y.; Enomoto, Y.; Narazaki, H.; Watari, E.; Tanaka, S.; Takahashi, H.; Yano, I.; Brenner, M.B.; Sugita, M. Cutting edge: major CD8 T cell response to live bacillus Calmette-Guerin is mediated by CD1 molecules. J. Immunol. 2003, 170, 5345-5348.

36. Wang, M.H.; Chen, Y.Q.; Gercken, J.; Ernst, M.; Bohle, A.; Flad, H.D.; Ulmer, A.J. Specific activation of human peripheral blood gamma/delta + lymphocytes by sonicated antigens of Mycobacterium tuberculosis: role in vitro in killing human bladder carcinoma cell lines. Scand. J. Immunol. 1993, 38, 239-246.

37. Higuchi, T.; Shimizu, M.; Owaki, A.; Takahashi, M.; Shinya, E.; Nishimura, T.; Takahashi, H. A possible mechanism of intravesical BCG therapy for human bladder carcinoma: involvement of innate effector cells for the inhibition of tumor growth. Cancer Immunol. Immunother. 2009, 58, 1245-1255.

38. Naoe, M.; Ogawa, Y.; Takeshita, K.; Morita, J.; Iwamoto, S.; Miyazaki, A.; Yoshida, H. Bacillus Calmette-Guerin-pulsed dendritic cells stimulate natural killer $\mathrm{T}$ cells and gammadeltaT cells. Int. J. Urol. 2007, 14, 532-538. 
39. Emoto, M.; Emoto, Y.; Buchwalow, I.B.; Kaufmann, S.H. Induction of IFN-gamma-producing $\mathrm{CD}^{+}$natural killer T cells by Mycobacterium bovis bacillus Calmette Guerin. Eur. J. Immunol . 1999, 29, 650-659.

40. Suttmann, H.; Riemensberger, J.; Bentien, G.; Schmaltz, D.; Stockle, M.; Jocham, D.; Bohle, A.; Brandau, S. Neutrophil granulocytes are required for effective Bacillus Calmette-Guerin immunotherapy of bladder cancer and orchestrate local immune responses. Cancer Res. 2006, 66, 8250-8257.

41. Rosevear, H.M.; Lightfoot, A.J.; O'Donnell, M.A.; Griffith, T.S. The role of neutrophils and TNF-related apoptosis-inducing ligand (TRAIL) in bacillus Calmette-Guerin (BCG) immunotherapy for urothelial carcinoma of the bladder. Cancer Metastasis Rev. 2009, 28, 345-353.

42. Klostergaard, J.; Stoltje, P.A.; Kull, F.C., Jr. Tumoricidal effector mechanisms of murine BCGactivated macrophages: Role of TNF in conjugation-dependent and conjugation-independent pathways. J. Leukoc. Biol. 1990, 48, 220-228.

43. Klostergaard, J.; Leroux, M.E.; Hung, M.C. Cellular models of macrophage tumoricidal effector mechanisms in vitro. Characterization of cytolytic responses to tumor necrosis factor and nitric oxide pathways in vitro. J. Immunol. 1991, 147, 2802-2808.

44. Schwamberger, G.; Flesch, I.; Ferber, E. Tumoricidal effector molecules of murine macrophages. Pathobiology 1991, 59, 248-253.

45. Ratliff, T.L.; Ritchey, J.K.; Yuan, J.J.; Andriole, G.L.; Catalona, W.J. T-cell subsets required for intravesical BCG immunotherapy for bladder cancer. J. Urol. 1993, 150, 1018-1023.

46. Wang, R.; Rogers, A.M.; Ratliff, T.L.; Russell, J.H. CD95-dependent bystander lysis caused by CD4+ T helper 1 effectors. J. Immunol. 1996, 157, 2961-2968.

47. Kitamura, H.; Torigoe, T.; Honma, I.; Sato, E.; Asanuma, H.; Hirohashi, Y.; Sato, N.; Tsukamoto, T. Effect of human leukocyte antigen class I expression of tumor cells on outcome of intravesical instillation of bacillus calmette-guerin immunotherapy for bladder cancer. Clin. Cancer Res. 2006, 12, 4641-4644.

48. Luo, Y.; Knudson, M.J. Mycobacterium bovis bacillus Calmette-Guerin-induced macrophage cytotoxicity against bladder cancer cells. Clin. Dev. Immunol. 2010, 2010, 357591.

49. Alexandroff, A.B.; Nicholson, S.; Patel, P.M.; Jackson, A.M. Recent advances in bacillus Calmette-Guerin immunotherapy in bladder cancer. Immunotherapy 2010, 2, 551-560.

50. Ratliff, T.L.; Ritchey, J.K.; Yuan, J.J.; Andriole, G.L.; Catalona, W.J. T-cell subsets required for intravesical BCG immunotherapy for bladder cancer. J. Urol. 1993, 150, 1018-1023.

51. Mustafa, T.; Phyu, S.; Nilsen, R.; Bjune, G.; Jonsson, R. Increased expression of Fas ligand on Mycobacterium tuberculosis infected macrophages: A potential novel mechanism of immune evasion by Mycobacterium tuberculosis? Inflammation 1999, 23, 507-521.

52. DesJardin, L.E.; Kaufman, T.M.; Potts, B.; Kutzbach, B.; Yi, H.; Schlesinger, L.S. Mycobacterium tuberculosis-infected human macrophages exhibit enhanced cellular adhesion with increased expression of LFA-1 and ICAM-1 and reduced expression and/or function of complement receptors, FcgammaRII and the mannose receptor. Microbiology 2002, 148, 3161-3171. 
53. Diehl, G.E.; Yue, H.H.; Hsieh, K.; Kuang, A.A.; Ho, M.; Morici, L.A.; Lenz, L.L.; Cado, D.; Riley, L.W.; Winoto, A. TRAIL-R as a negative regulator of innate immune cell responses. Immunity 2004, 21, 877-889.

54. Yamada, H.; Kuroda, E.; Matsumoto, S.; Matsumoto, T.; Yamada, T.; Yamashita, U. Prostaglandin E2 down-regulates viable Bacille Calmette-Guerin-induced macrophage cytotoxicity against murine bladder cancer cell MBT-2 in vitro. Clin. Exp. Immunol. 2002, 128, $52-58$.

55. Luo, Y.; Yamada, H.; Evanoff, D.P.; Chen, X. Role of Th1-stimulating cytokines in bacillus Calmette-Guerin (BCG)-induced macrophage cytotoxicity against mouse bladder cancer MBT-2 cells. Clin. Exp. Immunol. 2006, 146, 181-188.

56. Ayari, C.; LaRue, H.; Hovington, H.; Decobert, M.; Harel, F.; Bergeron, A.; Tetu, B.; Lacombe, L.; Fradet, Y. Bladder tumor infiltrating mature dendritic cells and macrophages as predictors of response to bacillus Calmette-Guerin immunotherapy. Eur. Urol. 2009, 55, 1386-1395.

57. Saban, M.R.; Simpson, C.; Davis, C.; Wallis, G.; Knowlton, N.; Frank, M.B.; Centola, M.; Gallucci, R.M.; Saban, R. Discriminators of mouse bladder response to intravesical Bacillus Calmette-Guerin (BCG). BMC Immunol. 2007, 8, 6.

58. Wang, L.; Yi, T.; Kortylewski, M.; Pardoll, D.M.; Zeng, D.; Yu, H. IL-17 can promote tumor growth through an IL-6-Stat3 signaling pathway. J. Exp. Med. 2009, 206, 1457-1464.

59. Burger, M.; Thiounn, N.; Denzinger, S.; Kondas, J.; Benoit, G.; Chapado, M.S.; Jimenz-Cruz, F.J.; Kisbenedek, L.; Szabo, Z.; Zsolt, D.; Grimm, M.O.; Romics, I.; Thuroff, J.W.; Kiss, T.; Tombal, B.; Wirth, M.; Munsell, M.; Mills, B.; Koh, T.; Sherman, J. The application of adjuvant autologous antravesical macrophage cell therapy vs. BCG in non-muscle invasive bladder cancer: a multicenter, randomized trial. J. Transl. Med. 2010, 8, 54.

60. Poppas, D.P.; Pavlovich, C.P.; Folkman, J.; Voest, E.E.; Chen, X.; Luster, A.D.; O'Donnell, M.A. Intravesical bacille Calmette-Guerin induces the antiangiogenic chemokine interferon-inducible protein 10. Urology 1998, 52, 268-275.

61. Reale, M.; Intorno, R.; Tenaglia, R.; Feliciani, C.; Barbacane, R.C.; Santoni, A.; Conti, P. Production of MCP-1 and RANTES in bladder cancer patients after bacillus Calmette-Guerin immunotherapy. Cancer Immunol. Immunother. 2002, 51, 91-98.

62. Bisiaux, A.; Thiounn, N.; Timsit, M.O.; Eladaoui, A.; Chang, H.H.; Mapes, J.; Mogenet, A.; Bresson, J.L.; Prie, D.; Bechet, S.; Baron, C.; Sadorge, C.; Thomas, S.; Albert, E.B.; Albert, P.S.; Albert, M.L. Molecular analyte profiling of the early events and tissue conditioning following intravesical bacillus calmette-guerin therapy in patients with superficial bladder cancer. J. Urol. 2009, 181, 1571-1580.

63. Luo, Y.; Chen, X.; O'Donnell, M.A. Mycobacterium bovis bacillus Calmette-Guerin (BCG) induces human CC- and CXC-chemokines in vitro and in vivo. Clin. Exp. Immunol. 2007, 147, 370-378.

64. Kumar, A.; Dubey, D.; Bansal, P.; Mandhani, A.; Naik, S. Urinary interleukin-8 predicts the response of standard and low dose intravesical bacillus Calmette-Guerin (modified Danish 1331 strain) for superficial bladder cancer. J. Urol. 2002, 168, 2232-2235. 
65. Videira, P.A.; Calais, F.M.; Correia, M.; Ligeiro, D.; Crespo, H.J.; Calais, F.; Trindade, H. Efficacy of bacille Calmette-Guerin immunotherapy predicted by expression of antigen-presenting molecules and chemokines. Urology 2009, 74, 944-950.

66. Heldwein, K.A.; Liang, M.D.; Andresen, T.K.; Thomas, K.E.; Marty, A.M.; Cuesta, N.; Vogel, S.N.; Fenton, M.J. TLR2 and TLR4 serve distinct roles in the host immune response against Mycobacterium bovis BCG. J. Leukoc. Biol. 2003, 74, 277-286.

67. von Meyenn, F.; Schaefer, M.; Weighardt, H.; Bauer, S.; Kirschning, C.J.; Wagner, H.; Sparwasser, T. Toll-like receptor 9 contributes to recognition of Mycobacterium bovis Bacillus Calmette-Guerin by Flt3-ligand generated dendritic cells. Immunobiology 2006, 211, 557-565.

68. Fricke, I.; Mitchell, D.; Mittelstadt, J.; Lehan, N.; Heine, H.; Goldmann, T.; Bohle, A.; Brandau, S. Mycobacteria induce IFN-gamma production in human dendritic cells via triggering of TLR2. J. Immunol. 2006, 176, 5173-5182.

69. Kemp, T.J.; Ludwig, A.T.; Earel, J.K.; Moore, J.M.; Vanoosten, R.L.; Moses, B.; Leidal, K.; Nauseef, W.M.; Griffith, T.S. Neutrophil stimulation with Mycobacterium bovis bacillus Calmette-Guerin (BCG) results in the release of functional soluble TRAIL/Apo-2L. Blood 2005, 106, 3474-3482.

70. Ludwig, A.T.; Moore, J.M.; Luo, Y.; Chen, X.; Saltsgaver, N.A.; O'Donnell, M.A.; Griffith, T.S. Tumor necrosis factor-related apoptosis-inducing ligand: A novel mechanism for Bacillus Calmette-Guerin-induced antitumor activity. Cancer Res. 2004, 64, 3386-3390.

71. Shelley, M.D.; Kynaston, H.; Court, J.; Wilt, T.J.; Coles, B.; Burgon, K.; Mason, M.D. A systematic review of intravesical bacillus Calmette-Guerin plus transurethral resection vs. transurethral resection alone in Ta and T1 bladder cancer. BJU Int. 2001, 88, 209-216.

72. Bohle, A.; Jocham, D.; Bock, P.R. Intravesical bacillus Calmette-Guerin versus mitomycin C for superficial bladder cancer: A formal meta-analysis of comparative studies on recurrence and toxicity. J. Urol. 2003, 169, 90-95.

73. Shelley, M.D.; Wilt, T.J.; Court, J.; Coles, B.; Kynaston, H.; Mason, M.D. Intravesical bacillus Calmette-Guerin is superior to mitomycin $\mathrm{C}$ in reducing tumour recurrence in high-risk superficial bladder cancer: a meta-analysis of randomized trials. BJU Int. 2004, 93, 485-490.

74. Han, R.F.; Pan, J.G. Can intravesical bacillus Calmette-Guerin reduce recurrence in patients with superficial bladder cancer? A meta-analysis of randomized trials. Urology 2006, 67, 1216-1223.

75. Malmstrom, P.U.; Sylvester, R.J.; Crawford, D.E.; Friedrich, M.; Krege, S.; Rintala, E.; Solsona, E.; Di Stasi, S.M.; Witjes, J.A. An individual patient data meta-analysis of the long-term outcome of randomised studies comparing intravesical mitomycin $\mathrm{C}$ versus bacillus Calmette-Guerin for non-muscle-invasive bladder cancer. Eur. Urol. 2009, 56, 247-256.

76. Jarvinen, R.; Kaasinen, E.; Sankila, A.; Rintala, E. Long-term efficacy of maintenance bacillus Calmette-Guerin versus maintenance mitomycin $\mathrm{C}$ instillation therapy in frequently recurrent TaT1 tumours without carcinoma in situ: A subgroup analysis of the prospective, randomised FinnBladder I study with a 20-year follow-up. Eur. Urol. 2009, 56, 260-265.

77. Duchek, M.; Johansson, R.; Jahnson, S.; Mestad, O.; Hellstrom, P.; Hellsten, S.; Malmstrom, P.U. Bacillus Calmette-Guerin is superior to a combination of epirubicin and interferon-alpha2b in the intravesical treatment of patients with stage T1 urinary bladder cancer. A prospective, randomized, Nordic study. Eur. Urol. 2010, 57, 25-31. 
78. Sylvester, R.J.; Brausi, M.A.; Kirkels, W.J.; Hoeltl, W.; Calais Da Silva, F.; Powell, P.H.; Prescott, S.; Kirkali, Z.; van de Beek, C.; Gorlia, T.; de Reijke, T.M. Long-term efficacy results of EORTC genito-urinary group randomized phase 3 study 30911 comparing intravesical instillations of epirubicin, bacillus Calmette-Guerin, and bacillus Calmette-Guerin plus isoniazid in patients with intermediate- and high-risk stage Ta T1 urothelial carcinoma of the bladder. Eur. Urol. 2010, 57, 766-773.

79. Sylvester, R.J.; van der Meijden, A.P.; Witjes, J.A.; Kurth, K. Bacillus calmette-guerin versus chemotherapy for the intravesical treatment of patients with carcinoma in situ of the bladder: a meta-analysis of the published results of randomized clinical trials. J. Urol. 2005, 174, 86-91.

80. Sylvester, R.J.; van der Meijden, A.P.; Lamm, D.L. Intravesical bacillus Calmette-Guerin reduces the risk of progression in patients with superficial bladder cancer: A meta-analysis of the published results of randomized clinical trials. J. Urol. 2002, 168, 1964-1970.

81. Bohle, A.; Bock, P.R. Intravesical bacille Calmette-Guerin versus mitomycin C in superficial bladder cancer: Formal meta-analysis of comparative studies on tumor progression. Urology 2004, 63, 682-687.

82. Babjuk, M.; Oosterlinck, W.; Sylvester, R.; Kaasinen, E.; Bohle, A.; Palou-Redorta, J.; Roupret, M. EAU Guidelines on Non-Muscle-Invasive Urothelial Carcinoma of the Bladder, the 2011 Update. Eur. Urol. 2011, 59, 997-1008.

83. Badalament, R.A.; Herr, H.W.; Wong, G.Y.; Gnecco, C.; Pinsky, C.M.; Whitmore, W.F., Jr.; Fair, W.R.; Oettgen, H.F. A prospective randomized trial of maintenance versus nonmaintenance intravesical bacillus Calmette-Guerin therapy of superficial bladder cancer. J. Clin. Oncol. 1987, 5, 441-449.

84. Hudson, M.A.; Ratliff, T.L.; Gillen, D.P.; Haaff, E.O.; Dresner, S.M.; Catalona, W.J. Single course versus maintenance bacillus Calmette-Guerin therapy for superficial bladder tumors: A prospective, randomized trial. J. Urol. 1987, 138, 295-298.

85. Akaza, H.; Hinotsu, S.; Aso, Y.; Kakizoe, T.; Koiso, K. Bacillus Calmette-Guerin treatment of existing papillary bladder cancer and carcinoma in situ of the bladder. Four-year results. The Bladder Cancer BCG Study Group. Cancer 1995, 75, 552-559.

86. Lamm, D.L.; Blumenstein, B.A.; Crissman, J.D.; Montie, J.E.; Gottesman, J.E.; Lowe, B.A.; Sarosdy, M.F.; Bohl, R.D.; Grossman, H.B.; Beck, T.M.; Leimert, J.T.; Crawford, E.D. Maintenance bacillus Calmette-Guerin immunotherapy for recurrent TA, T1 and carcinoma in situ transitional cell carcinoma of the bladder: A randomized Southwest Oncology Group Study. J. Urol. 2000, 163, 1124-1129.

87. Palou, J.; Laguna, P.; Millan-Rodriguez, F.; Hall, R.R.; Salvador-Bayarri, J.; Vicente-Rodriguez, J. Control group and maintenance treatment with bacillus Calmette-Guerin for carcinoma in situ and/or high grade bladder tumors. J. Urol. 2001, 165, 1488-1491.

88. Lamm, D.L.; Blumenstein, B.A.; Crawford, E.D.; Montie, J.E.; Scardino, P.; Grossman, H.B.; Stanisic, T.H.; Smith, J.A., Jr.; Sullivan, J.; Sarosdy, M.F.; et al. A randomized trial of intravesical doxorubicin and immunotherapy with bacille Calmette-Guerin for transitional-cell carcinoma of the bladder. N. Engl. J. Med. 1991, 325, 1205-1209.

89. Nepple, K.G.; Aubert, H.A.; Braasch, M.R.; O'Donnell, M.A. Combination of BCG and interferon intravesical immunotherapy: an update. World J. Urol. 2009, 27, 343-346. 
90. Nadler, R.B.; Catalona, W.J.; Hudson, M.A.; Ratliff, T.L. Durability of the tumor-free response for intravesical bacillus Calmette-Guerin therapy. J. Urol. 1994, 152, 367-373.

91. van der Meijden, A.P.; Sylvester, R.J.; Oosterlinck, W.; Hoeltl, W.; Bono, A.V. Maintenance Bacillus Calmette-Guerin for Ta T1 bladder tumors is not associated with increased toxicity: results from a European Organisation for Research and Treatment of Cancer Genito-Urinary Group Phase III Trial. Eur. Urol. 2003, 44, 429-434.

92. Sylvester, R.J.; van der Meijden, A.P.; Oosterlinck, W.; Hoeltl, W.; Bono, A.V. The side effects of Bacillus Calmette-Guerin in the treatment of Ta T1 bladder cancer do not predict its efficacy: results from a European Organisation for Research and Treatment of Cancer Genito-Urinary Group Phase III Trial. Eur. Urol. 2003, 44, 423-428.

93. Joudi, F.N.; Smith, B.J.; O'Donnell, M.A. Final results from a national multicenter phase II trial of combination bacillus Calmette-Guerin plus interferon alpha-2B for reducing recurrence of superficial bladder cancer. Urol. Oncol. 2006, 24, 344-348.

94. Nepple, K.G.; Lightfoot, A.J.; Rosevear, H.M.; O'Donnell, M.A.; Lamm, D.L. Bacillus Calmette-Guerin with or without interferon alpha-2b and megadose versus recommended daily allowance vitamins during induction and maintenance intravesical treatment of nonmuscle invasive bladder cancer. J. Urol. 2010, 184, 1915-1919.

95. Kaasinen, E.; Rintala, E.; Pere, A.K.; Kallio, J.; Puolakka, V.M.; Liukkonen, T.; Tuhkanen, K. Weekly mitomycin $\mathrm{C}$ followed by monthly bacillus Calmette-Guerin or alternating monthly interferon-alpha2B and bacillus Calmette-Guerin for prophylaxis of recurrent papillary superficial bladder carcinoma. J. Urol. 2000, 164, 47-52.

96. Correale, P.; Cusi, M.G.; Micheli, L.; Nencini, C.; Del Vecchio, M.T.; Torino, F.; Aquino, A.; Bonmassar, E.; Francini, G.; Giorgi, G. Chemo-immunotherapy of colorectal carcinoma: preclinical rationale and clinical experience. Invest. New Drugs 2006, 24, 99-110.

97. Liakou, C.I.; Narayanan, S.; Ng Tang, D.; Logothetis, C.J.; Sharma, P. Focus on TILs: Prognostic significance of tumor infiltrating lymphocytes in human bladder cancer. Cancer Immun. 2007, 7, 10.

98. Demaria, S.; Volm, M.D.; Shapiro, R.L.; Yee, H.T.; Oratz, R.; Formenti, S.C.; Muggia, F.; Symmans, W.F. Development of tumor-infiltrating lymphocytes in breast cancer after neoadjuvant paclitaxel chemotherapy. Clin. Canc. Res. 2001, 7, 3025-3030.

99. Ladoire, S.; Arnould, L.; Apetoh, L.; Coudert, B.; Martin, F.; Chauffert, B.; Fumoleau, P.; Ghiringhelli, F. Pathologic complete response to neoadjuvant chemotherapy of breast carcinoma is associated with the disappearance of tumor-infiltrating foxp3+ regulatory T cells. Clin. Canc. Res. 2008, 14, 2413-2420.

100. Lipponen, P.K.; Eskelinen, M.J.; Jauhiainen, K.; Harju, E.; Terho, R. Tumour infiltrating lymphocytes as an independent prognostic factor in transitional cell bladder cancer. Eur. J. Cancer 1992, 29A, 69-75.

101. Sharma, P.; Shen, Y.; Wen, S.; Yamada, S.; Jungbluth, A.A.; Gnjatic, S.; Bajorin, D.F.; Reuter, V.E.; Herr, H.; Old, L.J.; Sato, E. CD8 tumor-infiltrating lymphocytes are predictive of survival in muscle-invasive urothelial carcinoma. Proc. Natl. Acad. Sci. USA 2007, 104, 3967-3972.

102. Marits, P.; Karlsson, M.; Sherif, A.; Garske, U.; Thorn, M.; Winqvist, O. Detection of immune responses against urinary bladder cancer in sentinel lymph nodes. Eur. Urol. 2006, 49, 59-70. 
103. Schenk-Braat, E.A.; Bangma, C.H. Immunotherapy for superficial bladder cancer. Cancer Immunol. Immunother. 2005, 54, 414-423.

104. Sharma, P.; Bajorin, D.F.; Jungbluth, A.A.; Herr, H.; Old, L.J.; Gnjatic, S. Immune responses detected in urothelial carcinoma patients after vaccination with NY-ESO-1 protein plus BCG and GM-CSF. J. Immunother. 2008, 31, 849-857.

105. Honma, I.; Kitamura, H.; Torigoe, T.; Takahashi, A.; Tanaka, T.; Sato, E.; Hirohashi, Y.; Masumori, N.; Tsukamoto, T.; Sato, N. Phase I clinical study of anti-apoptosis protein survivin-derived peptide vaccination for patients with advanced or recurrent urothelial cancer. Cancer Immunol. Immunother. 2009, 58, 1801-1807.

106. Kitamura, H.; Torigoe, T.; Honma, I.; Asanuma, H.; Nakazawa, E.; Shimozawa, K.; Hirohashi, Y.; Sato, E.; Sato, N.; Tsukamoto, T. Expression and antigenicity of survivin, an inhibitor of apoptosis family member, in bladder cancer: implications for specific immunotherapy. Urology 2006, 67, 955-959.

107. Sherif, A.; Hasan, M.N.; Marits, P.; Karlsson, M.; Winqvist, O.; Thorn, M. Feasibility of T-cell-based adoptive immunotherapy in the first 12 patients with advanced urothelial urinary bladder cancer. Preliminary data on a new immunologic treatment based on the sentinel node concept. Eur. Urol. 2010, 58, 105-111.

108. Malmstrom, P.U.; Loskog, A.S.; Lindqvist, C.A.; Mangsbo, S.M.; Fransson, M.; Wanders, A.; Gardmark, T.; Totterman, T.H. AdCD40L immunogene therapy for bladder carcinoma-The first phase I/IIa trial. Clin. Cancer Res. 2010, 16, 3279-3287.

109. Matsumoto, K.; Noguchi, M.; Satoh, T.; Tabata, K.I.; Fujita, T.; Iwamura, M.; Yamada, A.; Komatsu, N.; Baba, S.; Itoh, K. A phase I study of personalized peptide vaccination for advanced urothelial carcinoma patients who failed treatment with methotrexate, vinblastine, adriamycin and cisplatin. BJU Int. 2010, doi: 10.1111/j.1464-410X.2010.09933.x.

110. Khong, H.T.; Restifo, N.P. Natural selection of tumor variants in the generation of "tumor escape" phenotypes. Nat. Immunol. 2002, 3, 999-1005.

111. Seliger, B.; Cabrera, T.; Garrido, F.; Ferrone, S. HLA class I antigen abnormalities and immune escape by malignant cells. Semin. Cancer Biol. 2002, 12, 3-13.

112. Homma, I.; Kitamura, H.; Torigoe, T.; Tanaka, T.; Sato, E.; Hirohashi, Y.; Masumori, N.; Sato, N.; Tsukamoto, T. Human leukocyte antigen class I down-regulation in muscle-invasive bladder cancer: its association with clinical characteristics and survival after cystectomy. Cancer. Sci. 2009, 100, 2331-2334.

113. Li, M.; Wang, H.; Xi, Z.; Xu, E.; Jiang, X.; Chen, J.; Shi, W. Reduction of major histocompatibility complex class I expression on bladder carcinoma following tumor antigen-pulsed dendritic cell vaccine: Implications for immunoresistance in therapy. Int. J. Urol. 2010, 17, 666-672.

114. Carretero, R.; Cabrera, T.; Gil, H.; Saenz-Lopez, P.; Maleno, I.; Aptsiauri, N.; Cozar, J.M.; Garrido, F. BCG immunotherapy of bladder cancer induces selection of HLA class I-deficient tumor cells. Int. J. Cancer 2011, 129, 839-846

115. Kitamura, H.; Torigoe, T.; Asanuma, H.; Honma, I.; Sato, N.; Tsukamoto, T. Down-regulation of HLA class I antigens in prostate cancer tissues and up-regulation by histone deacetylase inhibition. J. Urol. 2007, 178, 692-696. 
116. Du, C.; Wang, Y. The immunoregulatory mechanisms of carcinoma for its survival and development. J. Exp. Clin. Canc. Res. 2011, 30, 12.

117. Winerdal, M.E.; Marits, P.; Winerdal, M.; Hasan, M.; Rosenblatt, R.; Tolf, A.; Selling, K.; Sherif, A.; Winqvist, O. FOXP3 and survival in urinary bladder cancer. BJU Int. 2011, doi: 10.1111/j.1464-410X.2010.10020.x.

118. Eruslanov, E.; Neuberger, M.; Daurkin, I.; Perrin, G.Q.; Algood, C.; Dahm, P.; Rosser, C.; Vieweg, J.; Gilbert, S.M.; Kusmartsev, S. Circulating and tumor-infiltrating myeloid cell subsets in patients with bladder cancer. Int. J. Canc. Res. 2011, doi: 10.1002/ijc.26123.

119. Toes, R.E.; Blom, R.J.; Offringa, R.; Kast, W.M.; Melief, C.J. Enhanced tumor outgrowth after peptide vaccination. Functional deletion of tumor-specific CTL induced by peptide vaccination can lead to the inability to reject tumors. J. Immunol. 1996, 156, 3911-3918.

120. Toes, R.E.; Offringa, R.; Blom, R.J.; Melief, C.J.; Kast, W.M. Peptide vaccination can lead to enhanced tumor growth through specific T-cell tolerance induction. Proc. Natl. Acad. Sci. USA 1996, 93, 7855-7860.

121. Curigliano, G.; Rescigno, M.; Goldhirsch, A. Immunology and breast cancer: therapeutic cancer vaccines. Breast 2007, 16 (Suppl. 2), S20-S26.

(C) 2011 by the authors; licensee MDPI, Basel, Switzerland. This article is an open access article distributed under the terms and conditions of the Creative Commons Attribution license (http://creativecommons.org/licenses/by/3.0/). 